Cochrane Database of Systematic Reviews

\title{
Opioids for chronic non-cancer pain in children and adolescents
} (Review)

Cooper TE, Fisher E, Gray AL, Krane E, Sethna N, van Tilburg MAL, Zernikow B, Wiffen PJ

Cooper TE, Fisher E, Gray AL, Krane E, Sethna N, van Tilburg MAL, Zernikow B, Wiffen PJ.

Opioids for chronic non-cancer pain in children and adolescents.

Cochrane Database of Systematic Reviews 2017, Issue 7. Art. No.: CD012538.

DOI: 10.1002/14651858.CD012538.pub2.

www.cochranelibrary.com 
TABLE OF CONTENTS

HEADER 1

ABSTRACT

PLAIN LANGUAGE SUMMARY

BACKGROUND

OBJECTIVES

METHODS

Figure 1.

RESULTS

DISCUSSION

AUTHORS' CONCLUSIONS

ACKNOWLEDGEMENTS

REFERENCES

CHARACTERISTICS OF STUDIES

APPENDICES

WHAT'S NEW

HISTORY

CONTRIBUTIONS OF AUTHORS

DECLARATIONS OF INTEREST

SOURCES OF SUPPORT 
[Intervention Review]

\section{Opioids for chronic non-cancer pain in children and adolescents}

Tess E Cooper ${ }^{1}$, Emma Fisher², Andrew L Gray ${ }^{3}$, Elliot Krane ${ }^{4}$, Navil Sethna 5,6 , Miranda AL van Tilburg7 ${ }^{7}$ Boris Zernikow ${ }^{8}$, Philip J Wiffen ${ }^{9}$

${ }^{1}$ Cochrane Kidney and Transplant, Centre for Kidney Research, The Children's Hospital at Westmead, Westmead, Australia. ${ }^{2}$ Cochrane Pain, Palliative and Supportive Care Group, Pain Research Unit, Churchill Hospital, Oxford, UK. ${ }^{3}$ Division of Pharmacology, Discipline of Pharmaceutical Sciences, University of Kwazulu-Natal, Congella, South Africa. ${ }^{4}$ Anaesthesiology, Perioperative \& Pain Medicine, and Paediatrics, Stanford University, Stanford, CA, USA. ${ }^{5}$ Anesthesiology, Perioperative and Pain Medicine, Boston Children's Hospital, Boston, Massachusetts, USA. ${ }^{6}$ Mayo Family Pediatric Pain Rehabilitation Center, Boston Children's Hospital, Boston, Massachusetts, USA. ${ }^{7}$ College of Pharmacy and Health Sciences, Campbell University, Buies Creek, North Carolina, USA. 8German Paediatric Pain Centre, Children's and Adolescent's Hospital, Datteln, Germany. ${ }^{9}$ Thame, UK

Contact address: Tess E Cooper, Cochrane Kidney and Transplant, Centre for Kidney Research, The Children's Hospital at Westmead, Westmead, NSW, 2145, Australia. tess.cooper@sydney.edu.au.

Editorial group: Cochrane Pain, Palliative and Supportive Care Group.

Publication status and date: Stable (no update expected for reasons given in 'What's new'), published in Issue 2, 2020.

Citation: Cooper TE, Fisher E, Gray AL, Krane E, Sethna N, van Tilburg MAL, Zernikow B, Wiffen PJ. Opioids for chronic noncancer pain in children and adolescents. Cochrane Database of Systematic Reviews 2017, Issue 7. Art. No.: CD012538. DOI: 10.1002/14651858.CD012538.pub2.

Copyright ( 2020 The Cochrane Collaboration. Published by John Wiley \& Sons, Ltd.

\section{A B S T R A C T}

\section{Background}

Pain is a common feature of childhood and adolescence around the world, and for many young people, that pain is chronic. The World Health Organization guidelines for pharmacological treatments for children's persisting pain acknowledge that pain in children is a major public health concern of high significance in most parts of the world. While in the past, pain was largely dismissed and was frequently left untreated, views on children's pain have changed over time, and relief of pain is now seen as important.

We designed a suite of seven reviews on chronic non-cancer pain and cancer pain (looking at antidepressants, antiepileptic drugs, nonsteroidal anti-inflammatory drugs, opioids, and paracetamol as priority areas) in order to review the evidence for children's pain utilising pharmacological interventions in children and adolescents.

As the leading cause of morbidity in children and adolescents in the world today, chronic disease (and its associated pain) is a major health concern. Chronic pain (lasting three months or longer) can arise in the paediatric population in a variety of pathophysiological classifications: nociceptive, neuropathic, idiopathic, visceral, nerve damage pain, chronic musculoskeletal pain, and chronic abdominal pain, and other unknown reasons.

Opioids are used worldwide for the treatment of pain. They bind to opioid receptors in the central nervous system (mu, kappa, delta, and sigma) and can be agonists, antagonists, mixed agonist-antagonists, or partial agonists. Opioids are generally available in healthcare settings across most high-income countries, but access may be restricted in low- and middle-income countries. For example, opioids currently available in the UK include: buprenorphine, codeine, fentanyl, hydromorphone, methadone, morphine, oxycodone, and tramadol. Opioids are used in varying doses (generally based on body weight for paediatric patients) by means of parenteral, transmucosal, transdermal, or oral administration (immediate release or modified release). To achieve adequate pain relief in children using opioids, with an acceptable grade of adverse effects, the recommended method is a lower dose gradually titrated to effect in the child.

\section{Objectives}

To assess the analgesic efficacy and adverse events of opioids used to treat chronic non-cancer pain in children and adolescents aged between birth and 17 years, in any setting. 


\section{Search methods}

We searched the Cochrane Central Register of Controlled Trials (CENTRAL) via the Cochrane Library, MEDLINE via Ovid, and Embase via Ovid from inception to 6 September 2016. We also searched the reference lists of retrieved studies and reviews, and searched online clinical trial registries.

\section{Selection criteria}

Randomised controlled trials, with or without blinding, of any dose and any route, treating chronic non-cancer pain in children and adolescents, comparing opioids with placebo or an active comparator.

\section{Data collection and analysis}

Two review authors independently assessed studies for eligibility. We planned to use dichotomous data to calculate risk ratio and number needed to treat, using standard methods. We planned to assess GRADE (Grading of Recommendations Assessment, Development and Evaluation) and planned to create a 'Summary of findings' table.

\section{Main results}

No studies were eligible for inclusion in this review.

There is no evidence to support or refute the use of opioids for treating chronic non-cancer pain in children and adolescents.

\section{Authors' conclusions}

We are unable to comment about efficacy or harm from the use of opioids to treat chronic non-cancer pain in children and adolescents.

We know from adult randomised controlled trials that some opioids, such as morphine and codeine, can be effective in certain chronic pain conditions.

\section{PLAIN LANGUAGE SUMMARY}

\section{Opioids for chronic non-cancer pain in children and adolescents}

\section{Bottom line}

There is no evidence from randomised controlled trials to support or refute the suggestion that opioids in any dose will provide pain relief for children or adolescents with chronic non-cancer pain.

\section{Background}

Children can experience chronic or recurrent pain related to genetic conditions, damaged nerves, chronic musculoskeletal pain, and chronic abdominal pain, as well as for other unknown reasons. Chronic pain is pain that lasts three months or longer and is commonly accompanied by changes in lifestyle and functional abilities, as well as by signs and symptoms of depression and anxiety.

Opioids are used worldwide for the treatment of pain. Opioids are generally available in healthcare settings across most high-income countries, but access may be restricted in low- and middle-income countries. For example, opioids currently available in the UK include: buprenorphine, codeine, fentanyl, hydromorphone, methadone, morphine, oxycodone, and tramadol. Opioids are used in varying doses and are commonly administered via injection or oral tablets.

\section{Key results}

In September 2016 we searched for clinical trials where any opioids were used to treat chronic pain (potentially from either nerve pain, musculoskeletal problems, menstrual cramps, or abdominal discomfort).

We found no studies that met the requirements for this review. Several studies tested opioids in adults with chronic pain, but none in participants from birth to 17 years old.

\section{Quality of the evidence}

We planned to rate the quality of the evidence from studies using four levels: very low, low, moderate, or high. Very low quality evidence means that we are very uncertain about the results. High quality evidence means that we are very confident in the results.

We were unable to rate the quality of the evidence as there was no evidence from randomised controlled trials to support or refute the suggestion that opioids in any dose will reduce chronic non-cancer pain in children or adolescents. 


\section{B A C K G R O U N D}

Pain is a common feature of childhood and adolescence around the world, and for many young people, that pain is chronic. The World Health Organization guidelines for pharmacological treatments for persisting pain in children acknowledge that pain in children is a major public health concern of high significance in most parts of the world (WHO 2012). While in the past, pain was largely dismissed and was frequently left untreated, views on children's pain have changed over time, and relief of pain is now seen as important. Since the 1970s, studies comparing child and adult pain management have revealed a variety of responses to pain, fuelling the need for a more in-depth focus on paediatric pain (Caes 2016).

Infants (zero to 12 months), children (1 to 9 years), and adolescents (10 to 18 years), WHO 2012, account for $27 \%$ (1.9 billion) of the world's population (United Nations 2015); the proportion of those aged 14 years and under ranges from 12\% (in Hong Kong) to 50\% (in Niger) (World Bank 2014). However, little is known about the pain management needs of this population. For example, in the Cochrane Library, approximately 12 reviews produced by the Cochrane Pain, Palliative and Supportive Care Review Group in the past 18 years have been specifically concerned with children and adolescents, compared to over 100 reviews specific to adults. Additional motivating factors for investigating children's pain include the vast amount of unmanaged pain in the paediatric population and the development of new technologies and treatments. We convened an international group of leaders in paediatric pain to design a suite of seven reviews in chronic pain and cancer pain (looking at antidepressants, antiepileptic drugs, non-steroidal anti-inflammatory drugs, opioids, and paracetamol as priority areas) in order to review the evidence under a programme grant for children's pain utilising pharmacological interventions in children and adolescents (Appendix 1).

This review is based on a template for reviews of pharmacotherapies used to relieve pain in infants, children, and adolescents. The aim is for all reviews to use the same methods, based on new criteria for what constitutes reliable evidence (Appendix 2) (Moore 2010a; Moore 2012). This review focused on opioids to treat chronic non-cancer pain.

\section{Description of the condition}

This review focused on chronic non-cancer pain experienced by children and adolescents as a result of any type of chronic disease that occurs throughout the global paediatric population. Children's level of pain can be mild, moderate, or severe, and pain management is an essential element of patient management during all care stages of chronic disease.

As the leading cause of morbidity in children and adolescents in the world today, chronic disease (and its associated pain) is a major health concern. Chronic pain can arise in the paediatric population in a variety of pathophysiological classifications: nociceptive, neuropathic, idiopathic, or visceral. Chronic pain is pain that lasts three months or longer and is commonly accompanied by changes in lifestyle and functional abilities, as well as by signs and symptoms of depression and anxiety (Ripamonti 2008).

Whilst diagnostic and perioperative procedures performed to treat chronic diseases are a known common cause of pain in these patients, this review did not cover perioperative pain or adverse effects of treatments such as mucositis.

\section{Description of the intervention}

Opioids are used worldwide for the treatment of pain. They bind to opioid receptors in the central nervous system (mu, kappa, delta, and sigma) and can be agonists, antagonists, mixed agonistantagonists, or partial agonists. Opioids are generally available in healthcare settings across most high-income countries, but access may be restricted in low- and middle-income countries. For example, opioids currently available in the UK include: buprenorphine, codeine, fentanyl, hydromorphone, methadone, morphine, oxycodone, and tramadol.

Opioids are used in varying doses (generally based on body weight for paediatric patients) by means of parenteral or oral administration (immediate release or modified release). However, receiving injections or swallowing tablets can sometimes prove challenging in paediatric patients, in which case tablets can be crushed. Alternatively, buccal, transdermal, nasal, or rectal administration may also be adopted (Verghese 2010). To achieve adequate pain relief in children using opioids, with an acceptable grade of adverse effects, the recommended method is a lower dose gradually titrated to effect in the child (WHO 2012).

Adverse effects of analgesic opioids in children in the short term include: constipation, hives, nausea, pruritus, respiratory depression, and vomiting. The long-term potential for addiction and withdrawals is lessened due to controlled administration (Rosenblum 2008), and even fewer cases result in opioid tolerance, overdose, and more rarely, death.

\section{How the intervention might work}

Opioids act on opioid receptors. The four opioid receptors (mu, kappa, delta, and ORL-1) are distributed throughout the body in different densities, especially in nervous tissues. The peptides and receptors contribute to various physiological functions including the modulation of pain, the immune system, and hormones (PCF 2014). Opioid receptors are G-protein-coupled receptors and are located primarily in the central nervous system. Once agonistic opioids have bound to the opioid receptor, they produce intracellular effects throughout the coupled G-protein that result in an inhibition of the nociceptive transmission. Activation results in neural inhibition by decreasing the release of excitatory neurotransmitters from the presynaptic terminals (Verghese 2010). The clinically important opioid analgesics act as agonists at the mu-receptor, with some potential significant effects on deltaopioid receptors (e.g. methadone) and kappa-opioid receptors (e.g. oxycodone). Some opioids are mixed agonist-antagonists (e.g. buprenorphine). Some opioids also possess non-opioid activity (e.g. methadone, tapentadol, and tramadol) (PCF 2014).

\section{Why it is important to do this review}

The paediatric population is at risk of inadequate management of pain (AMA 2013). Some conditions that would be aggressively treated in adult patients are being managed with insufficient analgesia in younger populations (AMA 2013). Although there have been repeated calls for best evidence to treat children's pain, such as Eccleston 2003, there are no easily available summaries of the most effective paediatric pain relief. 
This review formed part of a Programme Grant addressing the unmet needs of people with chronic pain, commissioned by the National Institute for Health Research (NIHR) in the UK. This topic was identified in June 2015 during consultation with experts in paediatric pain. Please see Appendix 1 for full details of the meeting. The standards used to assess evidence in chronic pain trials have changed substantially in recent years, with particular attention being paid to trial duration, withdrawals, and statistical imputation following withdrawal, all of which can substantially alter estimates of efficacy. The most important change was to encourage a move from using average pain scores, or average change in pain scores, to the number of people who have a large decrease in pain (by at least 50\%). Pain intensity reduction of $50 \%$ or more has been shown to correlate with improvements in comorbid symptoms, function, and quality of life (Moore 2011a). These standards are set out in the reference guide for pain studies (AUREF 2012).

\section{OB JECTIVES}

To assess the analgesic efficacy and adverse events of opioids used to treat chronic non-cancer pain in children and adolescents aged between birth and 17 years, in any setting.

\section{METHODS}

\section{Criteria for considering studies for this review}

\section{Types of studies}

We planned to include randomised controlled trials, with or without blinding, and participant- or observer-reported outcomes.

Full journal publication was required, with the exception of online clinical trial results, summaries of otherwise unpublished clinical trials, and abstracts with sufficient data for analysis. We planned to include studies published in any language. We planned to exclude abstracts (usually meeting reports) or unpublished data, nonrandomised studies, studies of experimental pain, case reports, and clinical observations.

\section{Types of participants}

We planned to include studies of infants, children, and adolescents, aged from birth to 17 years old, with chronic or recurrent pain (lasting for three months or longer), arising from genetic conditions, neuropathy, or other conditions. These included but were not limited to chronic musculoskeletal pain and chronic abdominal pain.

We planned to exclude studies of perioperative pain, acute pain, cancer pain, headache, migraine, and pain associated with primary disease or its treatment. These topics are covered in their own respective reviews.

We planned to include studies of participants with more than one type of chronic pain, in which case we would analyse results according to the primary condition.

\section{Types of interventions}

We planned to include studies reporting interventions prescribing any opioid (alone or in combination) for the relief of chronic noncancer pain; by any route, in any dose, with comparison to a placebo or any active comparator.

\section{Types of outcome measures}

In order to be eligible for inclusion in this review, studies had to report pain assessment, as well as meeting the other selection criteria.

We planned to include trials measuring pain intensity and pain relief assessed using validated tools such as numerical rating scale (NRS), visual analogue scale (VAS), Faces Pain Scale - Revised (FPS$\mathrm{R})$, Colour Analogue Scale (CAS), or any other validated numerical rating scale.

We were particularly interested in Pediatric Initiative on Methods, Measurement, and Pain Assessment in Clinical Trials (PedIMMPACT) definitions for moderate and substantial benefit in chronic pain studies (PedIMMPACT 2008). These were defined as: at least 30\% pain relief over baseline (moderate); at least 50\% pain relief over baseline (substantial); much or very much improved on Patient Global Impression of Change scale (PGIC) (moderate); very much improved on PGIC (substantial).

These outcomes differ from those used in most earlier reviews, concentrating as they do on dichotomous outcomes where pain responses do not follow a normal (Gaussian) distribution. People with chronic pain desire high levels of pain relief, ideally more than $50 \%$ pain intensity reduction, and ideally having no worse than mild pain (Moore 2013a; O'Brien 2010).

We planned to record any reported adverse events. We planned to report the timing of outcome assessments.

\section{Primary outcomes}

1. Participant-reported pain relief of $30 \%$ or greater

2. Participant-reported pain relief of $50 \%$ or greater

3. PGIC much or very much improved

In the absence of self reported pain, we planned to consider the use of 'other-reported' pain, typically by an observer such as a parent, carer, or healthcare professional (Stinson 2006; von Baeyer 2007).

\section{Secondary outcomes}

We identified the following with reference to the PedIMMPACT recommendations, which suggest core outcome domains and measures for consideration in paediatric acute and chronic/ recurrent pain clinical trials (PedIMMPACT 2008).

1. Carer Global Impression of Change

2. Requirement for rescue analgesia

3. Sleep duration and quality

4. Acceptability of treatment

5. Physical functioning as defined by validated scales

6. Quality of life as defined by validated scales

7. Any adverse events

8. Withdrawals due to adverse events

9. Any serious adverse event. Serious adverse events typically include any untoward medical occurrence or effect that at any dose results in death, is life-threatening, requires hospitalisation or prolongation of existing hospitalisation, results in persistent or significant disability or incapacity, is a congenital anomaly or birth defect, is an 'important medical event' that may jeopardise 
the patient, or may require an intervention to prevent one of the above characteristics or consequences.

\section{Search methods for identification of studies}

We developed the search strategy based on previous strategies used by the Cochrane Pain, Palliative and Supportive Care Review Group and carried out the searches.

\section{Electronic searches}

We searched the following databases:

- Cochrane Central Register of Controlled Trials (CENTRAL) (via the Cochrane Library) searched 6 September 2016;

- MEDLINE (via Ovid) 1947 to September week 2 2016;Embase (via Ovid) 1974 to 2016 week 38.

We used medical subject headings (MeSH) or equivalent and text word terms. We restricted our search to randomised controlled trials and clinical trials. There were no language or date restrictions. We restricted our search to published papers only and excluded conference abstracts or meeting reports. The focus of the key words in our search terms was on chronic pain and opioids. We tailored searches to individual databases. The search strategies for MEDLINE, Embase, and CENTRAL are in Appendix 3, Appendix 4, and Appendix 5, respectively.

\section{Searching other resources}

We searched ClinicalTrials.gov (www.clinicaltrials.gov) and the World Health Organization International Clinical Trials Registry
Platform (WHO ICTRP) (apps.who.int/trialsearch/) for ongoing trials in June 2017. In addition, we checked reference lists of reviews and retrieved articles for additional studies, and performed citation searches on key articles. We planned to contact experts in the field for unpublished and ongoing trials. We planned to contact study authors for additional information where necessary.

\section{Data collection and analysis}

We planned to perform separate analyses according to particular chronic pain conditions. We planned to combine different chronic pain conditions in analyses for exploratory purposes only.

\section{Selection of studies}

Two review authors independently determined study eligibility by reading the abstract of each study identified by the search. Review authors independently eliminated studies that clearly did not satisfy the inclusion criteria, and obtained full copies of the remaining studies. Two review authors independently read these studies to select those that met the inclusion criteria, a third review author adjudicating in the event of disagreement. We did not anonymise the studies in any way before assessment. We included a PRISMA flow chart (Figure 1) to illustrate the results of the search and the process of screening and selecting studies for inclusion in the review (Moher 2009), as recommended in section 11.2.1 of the Cochrane Handbook for Systematic Reviews of Interventions (Higgins 2011). We planned to include studies in the review irrespective of whether measured outcome data were reported in a 'usable' way. 
Figure 1. Study flow diagram.

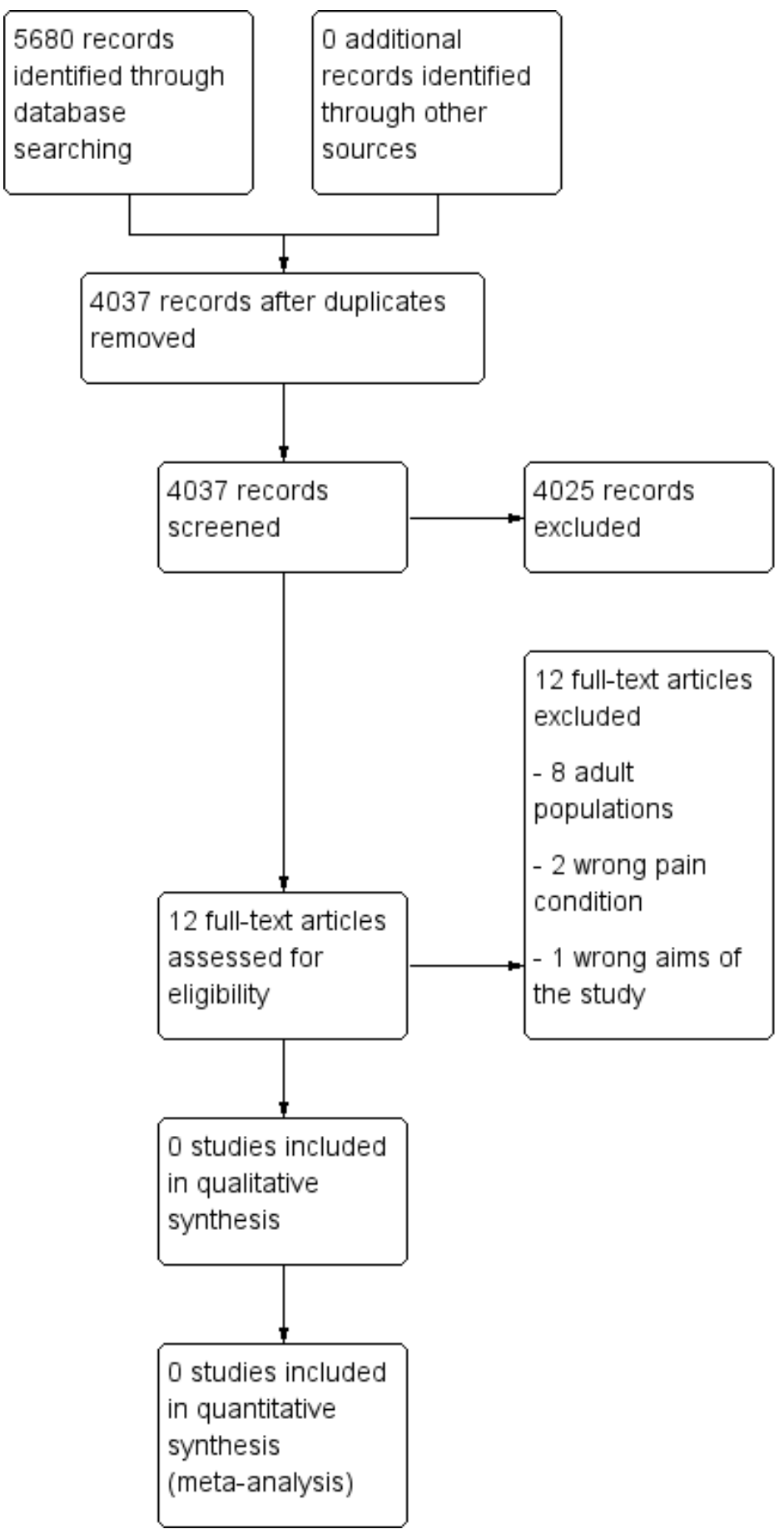

\section{Data extraction and management}

We planned to obtain full copies of the studies with two review authors independently carrying out data extraction. Where available, we would have extracted information about the pain condition, number of participants treated, drug and dosing regimen, study design (placebo or active control), study duration and follow-up, analgesic outcome measures and results, withdrawals, and adverse events (participants experiencing any adverse event or serious adverse event). We planned to collate multiple reports of the same study, so that each study rather than each report was the unit of interest in the review. We planned to collect characteristics of the included studies in sufficient detail to populate a 'Characteristics of included studies' table.

We planned to use a template data extraction form and check for agreement before entry into Cochrane's statistical software Review Manager 5 (RevMan 2014).

If a study had more than two intervention arms, we planned to only include the intervention and control groups that met the eligibility criteria. If multi-arm studies were included, we planned 
to analyse multiple intervention groups in an appropriate way that avoided arbitrary omission of relevant groups and double-counting of participants.

\section{Assessment of risk of bias in included studies}

We planned for two review authors to independently assess risk of bias for each study, using the criteria outlined in the Cochrane Handbook for Systematic Reviews of Interventions (Higgins 2011).

We planned to complete a 'Risk of bias' table for each included study using the Cochrane 'Risk of bias' tool in Review Manager 5 (RevMan 2014).

We planned to assess the following for each study. Any disagreements would have been resolved by discussion between review authors or by consulting a third review author when necessary.

1. Random sequence generation (checking for possible selection bias). We planned to assess the method used to generate the allocation sequence as: low risk of bias (i.e. any truly random process, e.g. random number table; computer random number generator); or unclear risk of bias (when the method used to generate the sequence was not clearly stated). We planned to exclude studies that used a non-random process and were therefore at high risk of bias (e.g. odd or even date of birth; hospital or clinic record number).

2. Allocation concealment (checking for possible selection bias). The method used to conceal allocation to interventions prior to assignment determines whether intervention allocation could have been foreseen in advance of, or during, recruitment, or changed after assignment. We planned to assess the methods as: low risk of bias (e.g. telephone or central randomisation; consecutively numbered, sealed, opaque envelopes); or unclear risk of bias (when the method was not clearly stated). We planned to exclude studies that did not conceal allocation and were therefore at a high risk of bias (e.g. open list).

3. Blinding of participants and personnel (checking for possible performance bias). We planned to assess any methods used to blind the participants and personnel from knowledge of which intervention a participant received. We planned to assess the methods as: low risk of bias (study states that the participants and personnel involved were blinded to treatment groups); unclear risk of bias (study does not state whether or not participants and personnel were blinded to treatment groups); or high risk of bias (participants or personnel were not blinded) (as stated in Types of studies, we planned to include trials with or without blinding, and participant- or observer-reported outcomes).

4. Blinding of outcome assessment (checking for possible detection bias). We planned to assess any methods used to blind the outcome assessors from knowledge of which intervention a participant received. We planned to assess the methods as: low risk of bias (e.g. study states that it was single-blinded and describes the method used to achieve blinding of the outcome assessor); unclear risk of bias (study states that outcome assessors were blinded but does not provide an adequate description of how this was achieved); or high risk of bias (outcome assessors were not blinded) (as stated in Types of studies, we planned to include trials with or without blinding, and participant- or observer-reported outcomes).
5. Incomplete outcome data (checking for possible attrition bias due to the amount, nature, and handling of incomplete outcome data). We planned to assess the methods used to deal with incomplete data as: low risk of bias (i.e. less than $10 \%$ of participants did not complete the study or 'baseline observation carried forward' (BOCF) analysis was used, or both); unclear risk of bias (used 'last observation carried forward' (LOCF) analysis); or high risk of bias (used 'completer' analysis).

6. Selective reporting (checking for possible reporting bias). We planned to assess the methods used to report the outcomes of the study as: low risk of bias (if all planned outcomes in the protocol or methods were reported in the results); unclear risk of bias (if there was not a clear distinction between planned outcomes and reported outcomes); high risk of bias (if some planned outcomes from the protocol or methods were clearly not reported in the results).

7. Size of study (checking for possible biases confounded by small size). We planned to assess studies as being at low risk of bias (200 participants or more per treatment arm); unclear risk of bias (50 to 199 participants per treatment arm); or high risk of bias (fewer than 50 participants per treatment arm).

8. Other bias. We planned to assess studies for any additional sources of bias as low, unclear, or high risk of bias, and provide rationale.

\section{Measures of treatment effect}

Where dichotomous data were available, we planned to calculate a risk ratio (RR) with $95 \%$ confidence interval $(\mathrm{Cl})$ and metaanalyse the data as appropriate. We planned to calculate number needed to treat for an additional beneficial outcome (NNTB) where appropriate (McQuay 1998); for unwanted effects the NNTB becomes the number needed to treat for an additional harmful outcome (NNTH) and is calculated in the same manner. Where continuous data were reported, we planned to use appropriate methods to combine these data in the meta-analysis.

\section{Unit of analysis issues}

We planned to accept randomisation to the individual participant only. We planned to split the control treatment arm between active treatment arms in a single study if the active treatment arms were not combined for analysis. We would only accept studies with minimum 10 participants per treatment arm.

\section{Dealing with missing data}

We planned to use intention-to-treat analysis where the intention-to-treat population consisted of participants who were randomised, took at least one dose of the assigned study medication, and provided at least one post baseline assessment. We would have assigned missing participants zero improvement wherever possible.

\section{Assessment of heterogeneity}

We planned to identify and measure heterogeneity as recommended in Chapter 9 of theCochrane Handbook for Systematic Reviews of Interventions (Higgins 2011). We planned to deal with clinical heterogeneity by combining studies that examined similar conditions. We planned to undertake and present a meta-analysis only if we judged participants, interventions, comparisons, and outcomes to be sufficiently similar to ensure a clinically meaningful answer. We planned to assess statistical 
heterogeneity visually and by using the $I^{2}$ statistic (L'Abbé 1987). When $I^{2}$ was greater than $50 \%$, we planned to consider the possible reasons.

\section{Assessment of reporting biases}

We planned to assess the risk of reporting bias, as recommended in chapter 8 of the Cochrane Handbook for Systematic Reviews of Interventions (Higgins 2011).

The aim of this review was to use dichotomous outcomes of known utility and of value to patients (Hoffman 2010; Moore 2010b; Moore 2010c; Moore 2010d; Moore 2013a). The review did not depend on what the authors of the original studies chose to report or not, though clearly difficulties would arise in studies failing to report any dichotomous results. We planned to extract and use continuous data, which probably reflected efficacy and utility poorly, and is useful for illustrative purposes only.

We planned to assess publication bias using a method designed to detect the amount of unpublished data with a null effect required to make any result clinically irrelevant (usually taken to mean a number needed to treat (NNT) of 10 or higher) (Moore 2008).

\section{Data synthesis}

We planned to use a fixed-effect model for meta-analysis. We planned to use a random-effects model for meta-analysis if there is significant clinical heterogeneity and we considered it appropriate to combine studies. We planned to conduct our analysis using the primary outcomes of pain and adverse events, and to calculate the NNTHs for adverse events. We planned to use the Cochrane software program Review Manager 5 (RevMan 2014).

\section{Quality of the evidence}

To analyse data, two review authors independently rated the quality of each outcome. We used the GRADE approach to assess the quality of the body of evidence related to each of the key outcomes. We planned to report our judgement in a 'Summary of findings' table per Chapter 12 of the Cochrane Handbook (Appendix 6) (Higgins 2011).

In addition, there may be circumstances where the overall rating for a particular outcome would need to be adjusted per GRADE guidelines (Guyatt 2013a). For example, if there were so few data that the results were highly susceptible to the random play of chance, or if studies used LOCF imputation in circumstances where there were substantial differences in adverse event withdrawals, one would have no confidence in the result, and would need to downgrade the quality of the evidence by three levels, to very low quality. In circumstances where no data were reported for an outcome, we planned to report that there was no evidence to support or refute (Guyatt 2013b).

\section{'Summary of findings' table}

We planned to include a 'Summary of findings' table as set out in the Cochrane Pain, Palliative and Supportive Care Review Group's author guide (AUREF 2012), and recommended in section 4.6.6 of the Cochrane Handbook for Systematic Reviews of Interventions (Higgins 2011). We planned to justify and document all assessments of the quality of the body of evidence.
In an attempt to interpret reliability of the findings for this systematic review, we planned to assess the summarised data using the GRADE guidelines (Appendix 6) to rate the quality of the body of evidence of each of the key outcomes listed in Types of outcome measures per Chapter 12 of the Cochrane Handbook (Guyatt 2011; Higgins 2011), as appropriate. Utilising the explicit criteria against study design, risk of bias, imprecision, inconsistency, indirectness, and magnitude of effect, we planned to summarise the evidence in an informative, transparent, and succinct 'Summary of findings' table or 'Evidence profile' table (Guyatt 2011).

\section{Subgroup analysis and investigation of heterogeneity}

We planned to perform subgroup analyses where a minimum number of data were available (at least 200 participants per treatment arm). We planned to analyse according to age group; type of drug; geographical location or country; type of control group; baseline measures; frequency, dose, and duration of drugs; and nature of drug.

We planned to investigate whether the results of subgroups were significantly different by inspecting the overlap of confidence intervals and by performing the test for subgroup differences available in Review Manager 5.

\section{Sensitivity analysis}

We did not plan to carry out any sensitivity analysis because the evidence base is known to be too small to allow reliable analysis; we did not plan to pool results from chronic pain of different origins in the primary analyses. We planned to examine details of dose escalation schedules in the unlikely circumstance that this could provide some basis for a sensitivity analysis.

\section{RE S U L T S}

\section{Description of studies}

\section{Results of the search}

A PRISMA flow diagram of the search results is shown in Figure 1.

Searches of the three main databases revealed 5680 records of titles and abstracts, of which 1643 duplicates were removed. Our searches of ClinicalTrials.gov and the WHO ICTRP yielded no additional eligible studies.

We screened the remaining 4037 titles and abstracts for eligibility, removing 4025 as ineligible studies.

We read the full texts of the remaining 12 studies, of which all 12 were found to be ineligible and excluded. We identified no ongoing studies. No studies fulfilled the inclusion criteria or were eligible to be entered into a quantitative analysis.

\section{Included studies}

No studies met our inclusion criteria for this review.

\section{Excluded studies}

See Characteristics of excluded studies.

We excluded 12 studies in this review. Eight were of adult populations (Argoff 2015; Berry 1975; Coutinho 1975; Daniel 1971; Gilbert 1978; Lapane 2013; Mehl-Madrona 1999; Middleton 1985), 
three evaluated acute pain (either abdominal or fracture injury) (Frohna 2005; Poonai 2014; Rose 2003), and one study did not investigate opioids (Valkenburg 2015)

\section{Risk of bias in included studies}

No studies were eligible for inclusion in this review, therefore we did not perform a 'Risk of bias' assessment.

\section{Effects of interventions}

No studies were eligible for inclusion in this review, therefore we were not able to comment on the efficacy or harm from the use of opioids to treat chronic non-cancer pain in children and adolescents.

Due to the lack of evidence in this field, we were unable to judge the quality of evidence. There is no evidence to support or refute the use of opioids for treating chronic non-cancer pain in children and adolescents.

\section{DISCUSSION}

\section{Summary of main results}

We were unable to find any randomised controlled trials for inclusion in this review and so could not assess the efficacy or adverse events of opioid interventions to treat chronic non-cancer pain in children and adolescents. There are known negative issues (as mentioned previously) related to the use of opioids for chronic non-cancer pain in adults that may well apply to children, so caution is advised (Stannard 2016).

\section{Overall completeness and applicability of evidence}

As we could identify no randomised controlled trials, we are unable to comment about efficacy or harm from the use of opioids to treat chronic non-cancer pain in children and adolescents. Similarly, we cannot comment on our remaining secondary outcomes: Carer Global Impression of Change; requirement for rescue analgesia; sleep duration and quality; acceptability of treatment; physical functioning; and quality of life.

\section{The suite of reviews}

This review is part of a suite of reviews on pharmacological interventions for chronic pain and cancer-related pain in children and adolescents (Appendix 1). Taking a broader view on this suite of reviews, some pharmacotherapies (investigated in our other reviews) are likely to provide more data than others. The results were thus as expected considering that randomised controlled trials in children are known to be limited. The results have the potential to inform policymaking decisions for funding future clinical trials into opioid treatment of child and adolescent pain, therefore any results (large or small) are important in order to capture a snapshot of the current evidence for opioids.

\section{Quality of the evidence}

Due to the lack of evidence in this field, we were unable to judge the quality of evidence. There is no evidence to support or refute the use of opioids for treating chronic non-cancer pain in children and adolescents.

This review shows that there is an absence of evidence from randomised controlled trials that opioids are effective in the management of chronic non-cancer pain in children. While it may be the case that this absence of evidence reflects the inadequacy of opioids for this purpose and that their use as monotherapy analgesics is more likely to cause harm than benefit, the opposite may also pertain, as the data are lacking. It is difficult to conduct long-term randomised controlled trials in children with chronic non-cancer conditions, and few observational/clinical data have been published.

\section{Potential biases in the review process}

We carried out extensive searches of major databases using broad search criteria, and also searched two large clinical trial registries. We consider it to be unlikely that we have missed relevant studies.

\section{Agreements and disagreements with other studies or reviews}

We were not able to identify any published systematic reviews on this topic.

\section{AUTHORS' CONCLUSIONS}

\section{Implications for practice}

\section{General}

We identified no randomised controlled trials to support or refute the use of opioids to treat chronic non-cancer pain in children and adolescents.

This is disappointing as children and adolescents have specific needs for analgesia. Extrapolating from adult data may be possible but could compromise effectiveness and safety.

Despite the lack of evidence of long-term effectiveness and safety, clinicians prescribe opioids to children and adolescents when medically necessary, based on historical and clinical experience, and on extrapolation from adult guidelines (e.g. Centers for Disease Control and Prevention guidelines, Dowell 2016), when perceived benefits in conjunction with other multimodalities improve a child's care. Appropriate medical management is necessary in disease-specific conditions such as incurable progressive degenerative conditions of Duchenne muscular dystrophy, osteogenesis imperfecta, congenital degenerative spine conditions, erythromelalgia, and neurodegenerative conditions such as spasticity/dystonia in mitochondrial Leigh's disease, leukoencephalopathy, and severe cerebral palsy.

In current practice, despite the lack of evidence, opioids are sometimes given to young children and adolescents with chronic non-cancer pain. Concerns about the use of opioids for chronic noncancer pain in adults need to be taken into consideration (Stannard 2016). We identified no guidelines for the use of opioids in chronic non-cancer pain in the paediatric population.

\section{For children with chronic non-cancer pain}

The amount of evidence around the use of opioids for treating chronic non-cancer pain is low. This means that at present, treatment is based on clinical experience and advice from respected authorities. We could make no judgement about adverse events or withdrawals. 


\section{For clinicians}

The amount of evidence around the use of opioids for treating chronic non-cancer pain is low. This means that at present, treatment is based on clinical experience and advice from respected authorities. We could make no judgement about adverse events or withdrawals.

\section{For policymakers}

The amount of evidence around the use of opioids for treating chronic non-cancer pain is low. This means that at present, treatment is based on clinical experience and advice from respected authorities. We could make no judgement about adverse events or withdrawals.

\section{For funders}

The amount of evidence around the use of opioids for treating chronic non-cancer pain is low. This means that at present, treatment is based on clinical experience and advice from respected authorities. We could make no judgement about adverse events or withdrawals.

\section{Implications for research}

\section{General}

The heterogenous nature of pain in children at various developmental ages needs to be recognised and presents challenges in designing research studies.

Overall, there appears to be a gap between what is done in practice and what is investigated in prospective clinical trials for treating children's and adolescents' pain with opioids. Some potential reasons for the lack of randomised controlled trials in children include: low prevalence of chronic pain disorders; parental reluctance of their child being randomised to ineffective treatment (e.g. placebo); small market share for analgesic agents; and lack of industry funding incentives, as most opioids are generic and prescribed in children in clinical practice.

The lack of evidence highlighted in this review implies that there is a need to fund and support suitable research for the treatment of chronic non-cancer pain in children and adolescents.

\section{Design}

Several methodological issues stand out.

The first is the use of outcomes of value to children with chronic non-cancer pain. Existing trials are designed more for purposes of registration and marketing than informing and improving clinical practice, that is the outcomes are often average pain scores or statistical differences, and rarely how many individuals achieve satisfactory pain relief. In the case where pain is initially mild or moderate, consideration needs to be given to what constitutes a satisfactory outcome. The situation differs somewhat to that of strong opioids that are used for moderate to severe cancer pain.
The second issue is the time taken to achieve good pain relief. We have no information about what constitutes a reasonable time to achieve a satisfactory result. This may best be approached initially with a Delphi methodology.

The third issue is design. Studies with a cross-over design often have significant attrition, therefore parallel-group designs may be preferable.

The fourth issue is size. The studies need to be suitably powered to ensure adequate data after the effect of attrition due to various causes. Much larger studies of several hundred participants or more are needed.

The fifth issue is ethics. Studies that randomise an opioid arm against a placebo arm will not likely meet ethical standards that protect vulnerable populations. Future studies must randomise against an active control, such as a non-steroidal anti-inflammatory drug with adequate provision for opioid rescue.

There are some other design issues that might be addressed. Most important might well be a clear decision concerning the goldstandard treatment comparator.

An alternative approach may be to design large registry studies. This could provide an opportunity to foster collaboration among paediatric clinicians and researchers, in order to create an evidence base.

\section{Measurement (endpoints)}

Trials need to consider the additional endpoint of 'no worse than mild pain' as well as the standard approaches to pain assessment.

\section{Other}

The obvious study design of choice is the prospective randomised trial, but other pragmatic designs may be worth considering. Studies could incorporate initial randomisation but a pragmatic design in order to provide immediately relevant information on effectiveness and costs. Such designs in pain conditions have been published (Moore 2010e).

\section{ACKNOWLEDGEMENTS}

We acknowledge the contribution of Christopher Eccleston to the template protocol.

We thank Andrew Moore, Cathy Stannard, Neil Schechter, and Marie-Claude Gregorie for peer reviewing.

Cochrane Review Group funding acknowledgement: the National Institute for Health Research (NIHR) is the largest single funder of the Cochrane Pain, Palliative and Supportive Care Review Group. Disclaimer: the views and opinions expressed herein are those of the authors and do not necessarily reflect those of the NIHR, National Health Service (NHS), or the Department of Health. 


\section{RE F E R E N C E S}

\section{References to studies excluded from this review}

\section{Argoff 2015 \{published data only\}}

Argoff C, Arnstein P, Stanos S, Robinson CY, Galer BS, Gould E, et al. Relationship between change in pain intensity and functional outcomes in patients with chronic pain receiving twice daily extended-release hydrocodone bitartrate. Journal of Opioid Management 2015;11(5):417-24.

\section{Berry 1975 \{published data only\}}

Berry FN, Miller JM, Levin HM, Bare WW, Hopkinson JH, Feldman AJ. Relief of severe pain with acetaminophen in a new dose formulation versus propoxyphene hydrochloride $65 \mathrm{mg}$. and placebo: a comparative double-blind study. Current Therapeutic Research, Clinical and Experimental 1975;17(4):361-8.

\section{Coutinho 1975 \{published data only\}}

Coutinho A, Bonelli J, de Carvalho PC. A double-blind comparative study of the analgesic effects of fenbufen, codeine, aspirin, propoxyphene and placebo. Current Therapeutic Research, Clinical and Experimental 1976;19(1):58-65.

Daniel 1971 \{published data only\}

Daniel JR, Wilkins RD, Nicholson PA. Two comparisons of the analgesic activity of orally administered pentazocine, dihydrocodeine and placebo. British Journal of Anaesthesia 1971;43(4):392-9.

\section{Frohna 2005 \{published data only\}}

Frohna JG. Oxycodone vs placebo in children with undifferentiated abdominal pain. Journal of Pediatrics 2005;147(3):408.

\section{Gilbert 1978 \{published data only\}}

Gilbert MM, Sanzari NP, Losada M, Caruso FS. Double-blind oral analgesic study of butorphanol in musculoskeletal pain: a comparison with codeine and placebo. Journal of International Medical Research 1978;6(1):14-23.

\section{Lapane 2013 \{published data only\}}

Lapane KL, Quilliam BJ, Benson C, Chow W, Kim MS. Gastrointestinal events after opioid treatment in nonmalignant pain: correlates of occurrence and impact on health-related quality of life. Journal of Opioid Management 2013;9(3):205-16.

\section{Mehl-Madrona 1999 \{published data only\}}

Mehl-Madrona LE. Comparison of ketorolac-chlorpromazine with meperidine-promethazine for treatment of exacerbations of chronic pain. Journal of the American Board of Family Practice 1999;12(3):188-94.

\section{Middleton 1985 \{published data only\}}

Middleton RS, Clyne MJ. A comparative study of Propain and a dextropropoxyphene/paracetamol combination analgesic. British Journal of Clinical Practice 1985;39(1):21-4.
Poonai 2014 \{published data only\}

Poonai N, Bhullar G, Lin K, Paini A, Mainprize D, Howard J, et al. Oral administration of morphine versus ibuprofen to manage postfracture pain in children: a randomized trial. Canadian Medical Association Journal 2014;186(17):1358-63.

\section{Rose 2003 \{published data only\}}

Rose JB, Finkel JC, Arquedas-Mohs A, Himelstein BP, Schreiner M, Medve RA. Oral tramadol for the treatment of pain of 7-30 days' duration in children. Anesthesia \& Analgesia 2003;96(1):78-81.

\section{Valkenburg 2015 \{published data only\}}

Valkenburg AJ, van den Bosch GE, de Graaf J, van Lingen RA, Wiesglas-Kuperus N, van Rosmalen J. Long-term effects of neonatal morphine infusion on pain sensitivity: follow-up of a randomized controlled trial. Journal of Pain 2015;16(9):926-33.

\section{Additional references}

AMA 2013

American Medical Association. Pediatric pain management. https://www.ama-assn.org/ 2013 (accessed 25 January 2016).

\section{AUREF 2012}

Cochrane Pain, Palliative and Supportive Care Group. PaPaS author and referee guidance. papas.cochrane.org/papasdocuments 2012 (accessed 16 July 2016).

\section{Caes 2016}

Caes L, Boemer KE, Chambers CT, Campbell-Yeo M, Stinson J, Birnie KA, et al. A comprehensive categorical and bibliometric analysis of published research articles on pediatric pain from 1975 to 2010. Pain 2016;157(2):302-13. [DOI: 10.1097/ j.pain.0000000000000403]

\section{Cooper 2017a}

Cooper TE, Heathcote L, Clinch J, Gold J, Howard R, Lord S, et al. Antidepressants for chronic non-cancer pain in children and adolescents. Cochrane Database of Systematic Reviews 2017, Issue 8. [DOI: 10.1002/14651858.CD012535.pub2]

\section{Cooper 2017b}

Cooper TE, Heathcote L, Anderson B, Gregoire MC, Ljungman G, Eccleston C. Non-steroidal anti-inflammatory drugs (NSAIDs) for cancer-related pain in children and adolescents. Cochrane Database of Systematic Reviews 2017, Issue 7. [DOI: 10.1002/14651858.CD012563.pub2]

\section{Cooper 2017c}

Cooper TE, Fisher E, Anderson B, Wilkinson N, Williams G, Eccleston C. Paracetamol (acetaminophen) for chronic non-cancer pain in children and adolescents. Cochrane Database of Systematic Reviews 2017, Issue 8. [DOI: 10.1002/14651858.CD012539.pub2] 


\section{Dowell 2016}

Dowell D, Haegerich TM, Chou R. CDC guideline for prescribing opioids for chronic pain - United States, 2016. JAMA

2016;315(15):1624-45.

\section{Dworkin 2008}

Dworkin RH, Turk DC, Wyrwich KW, Beaton D, Cleeland CS, Farrar JT, et al. Interpreting the clinical importance of treatment outcomes in chronic pain clinical trials: IMMPACT recommendations. Journal of Pain 2008;9(2):105-21. [DOI: 10.1016/j.jpain.2007.09.005]

\section{Eccleston 2003}

Eccleston C, Malleson PM. Management of chronic pain in children and adolescents (Editorial). BMJ 2003;326:1408-9.

\section{Eccleston 2017}

Eccleston C, Cooper TE, Fisher E, Anderson B, Wilkinson N. Non-steroidal anti-inflammatory drugs (NSAIDs) for chronic non-cancer pain in children and adolescents. Cochrane Database of Systematic Reviews 2017, Issue 8. [DOI: 10.1002/14651858.CD012537.pub2]

\section{Guyatt 2008}

Guyatt GH, Oxman AD, Vist GE, Kunz R, Falck-Ytter Y, AlonsoCoello $P$, et al. GRADE: an emerging consensus on rating quality of evidence and strength of recommendations. $B M J$ 2008;336:924-6. [DOI: 10.1136/bmj.39489.470347.AD]

\section{Guyatt 2011}

Guyatt G, Oxman AD, Akl EA, Kunz R, Vist G, Brozek J, et al. GRADE guidelines: 1 . Introduction - GRADE evidence profiles and summary of findings tables. Journal of Clinical Epidemiology 2011;64:383-94. [DOI: 10.1016/ j.jclinepi.2010.04.026]

\section{Guyatt 2013a}

Guyatt G, Oxman AD, Sultan S, Brozek J, Glasziou P, AlonsoCoelle $P$, et al. Making an overall rating of the confidence in effect estimates for a single outcome and for all outcomes. Journal of Clinical Epidemiology 2013;66(2):151-7. [DOI: 10.1016/ j.jclinepi.2012.01.006]

\section{Guyatt 2013b}

Guyatt GH, Oxman AD, Santesso N, Helfand M, Vist G, Kunz R, et al. GRADE guidelines: 12 . Preparing summary of findings tables - binary outcomes. Journal of Clinical Epidemiology 2013;66(2):158-72. [DOI: 10.1016/j.jclinepi.2012.01.012]

\section{Higgins 2011}

Higgins JPT, Green S (editors). Cochrane Handbook for Systematic Reviews of Interventions Version 5.1.0 (updated March 2011). The Cochrane Collaboration, 2011. Available from handbook.cochrane.org.

\section{Hoffman 2010}

Hoffman DL, Sadosky A, Dukes EM, Alvir J. How do changes in pain severity levels correspond to changes in health status and function in patients with painful diabetic peripheral neuropathy?. Pain 2010;149(2):194-201. [DOI: 10.1016/ j.pain.2009.09.017]

\section{L'Abbé 1987}

L'Abbé KA, Detsky AS, O'Rourke K. Meta-analysis in clinical research. Annals of Internal Medicine 1987;107:224-33.

\section{McQuay 1998}

McQuay H, Moore R. An Evidence-based Resource for Pain Relief. Oxford (UK): Oxford University Press, 1998.

\section{Moher 2009 \\ Moher D, Liberati A, Tetzlaff J, Altman DG, the PRISMA Group. Preferred reporting items for systematic reviews and meta-analyses: the PRISMA statement. PLoS Medicine 2009;6(7):e1000097.}

\section{Moore 2008}

Moore RA, Barden J, Derry S, McQuay HJ. Managing potential publication bias. In: McQuay HJ, Kalso E, Moore RA editor(s). Systematic Reviews in Pain Research: Methodology Refined. Seattle (WA): IASP Press, 2008:15-24. [ISBN: 978-0-931092-69-5]

\section{Moore 2009}

Moore RA, Straube S, Wiffen PJ, Derry S, McQuay HJ. Pregabalin for acute and chronic pain in adults. Cochrane Database of Systematic Reviews 2009, Issue 3. [DOI: 10.1002/14651858.CD007076.pub2]

\section{Moore 2010a}

Moore RA, Eccleston C, Derry S, Wiffen P, Bell RF, Straube S, et al. "Evidence" in chronic pain - establishing best practice in the reporting of systematic reviews. Pain 2010;150(3):386-9. [DOI: 10.1016/j.pain.2010.05.011]

\section{Moore 2010b}

Moore RA, Straube S, Paine J, Phillips CJ, Derry S, McQuay HJ. Fibromyalgia: moderate and substantial pain intensity reduction predicts improvement in other outcomes and substantial quality of life gain. Pain 2010;149(2):360-4.

\section{Moore 2010c}

Moore RA, Moore OA, Derry S, Peloso PM, Gammaitoni AR, Wang $\mathrm{H}$. Responder analysis for pain relief and numbers needed to treat in a meta-analysis of etoricoxib osteoarthritis trials: bridging a gap between clinical trials and clinical practice. Annals of the Rheumatic Diseases 2010;69(2):374-9. [DOI: 10.1136/ard.2009.107805]

\section{Moore 2010d}

Moore RA, Smugar SS, Wang H, Peloso PM, Gammaitoni A. Numbers-needed-to-treat analyses - do timing, dropouts, and outcome matter? Pooled analysis of two randomized, placebocontrolled chronic low back pain trials. Pain 2010;151(3):592-7. [DOI: 10.1016/j.pain.2010.07.2013]

\section{Moore 2010e}

Moore RA, Derry S, McQuay HJ, Straube S, Aldington D, Wiffen P, et al. ACTINPAIN writing group of the IASP Special Interest Group (SIG) on Systematic Reviews in Pain Relief. Clinical effectiveness: an approach to clinical trial design more relevant to clinical practice, acknowledging the importance of individual differences. Pain 2010;149:173-6. [PUBMED: 19748185] 


\section{Moore 2011a}

Moore RA, Straube S, Paine J, Derry S, McQuay HJ. Minimum efficacy criteria for comparisons between treatments using individual patient meta-analysis of acute pain trials: examples of etoricoxib, paracetamol, ibuprofen, and ibuprofen/ paracetamol combinations after third molar extraction. Pain 2011;152(5):982-9. [DOI: 10.1016/j.pain.2010.11.030]

\section{Moore 2011b}

Moore RA, Mhuircheartaigh RJ, Derry S, McQuay HJ. Mean analgesic consumption is inappropriate for testing analgesic efficacy in post-operative pain: analysis and alternative suggestion. European Journal of Anaesthesiology 2011;28(6):427-32. [DOI: 10.1097/EJA.0b013e328343c569]

\section{Moore 2012}

Moore RA, Straube S, Eccleston C, Derry S, Aldington D, Wiffen P, et al. Estimate at your peril: imputation methods for patient withdrawal can bias efficacy outcomes in chronic pain trials using responder analyses. Pain 2012;153(2):265-8. [DOI: 10.1016/j.pain.2011.10.004]

\section{Moore 2013a}

Moore RA, Straube S, Aldington D. Pain measures and cut-offs - 'no worse than mild pain' as a simple, universal outcome. Anaesthesia 2013;68(4):400-12. [DOI: 10.1111/anae.12148]

\section{Moore 2013b}

Moore A, Derry S, Eccleston C, Kalso E. Expect analgesic failure; pursue analgesic success. BMJ 2013;346:f2690. [DOI: 10.1136/ bmj.f2690]

\section{Moore 2014a}

Moore RA, Derry S, Taylor RS, Straube S, Phillips CJ. The costs and consequences of adequately managed chronic non-cancer pain and chronic neuropathic pain. Pain Practice 2014;14(1):79-94.

\section{Moore 2014b}

Moore RA, Cai N, Skljarevski V, Tölle TR. Duloxetine use in chronic painful conditions - individual patient data responder analysis. European Journal of Pain 2014;18(1):67-75. [DOI: 10.1002/j.1532-2149.2013.00341.x]

\section{O'Brien 2010}

O'Brien EM, Staud RM, Hassinger AD, McCulloch RC, Craggs JG, Atchinson JW, et al. Patient-centered perspective on treatment outcomes in chronic pain. Pain Medicine 2010;11(1):6-15. [DOI: 10.1111/j.1526-4637.2009.00685.x]

\section{PCF 2014}

Twycross R, Wilcock A, Howard P. Palliative care formulary. palliativedrugs.com 2014 (accessed 20 September 2016).

\section{PedIMMPACT 2008}

McGrath PJ, Walco GA, Turk DC, Dworking RH, Brown MT, Davidson $\mathrm{K}$, et al. Core outcome domains and measures for pediatric acute and chronic/recurrent pain clinical trials: PedIMMPACT. Journal of Pain 2008;9(9):771-83.

\section{RevMan 2014 [Computer program]}

Nordic Cochrane Centre, The Cochrane Collaboration. Review Manager (RevMan). Version 5.3. Copenhagen: Nordic Cochrane Centre, The Cochrane Collaboration, 2014.

\section{Ripamonti 2008}

Ripamonti C, Bandieri E. Pain therapy. Journal of Oncology and Hematology 2008;70:145-59. [DOI: 10.1016/ j.critrevonc.2008.12.005]

\section{Rosenblum 2008}

Rosenblum A, Marsch LA, Joseph H, Portenoy RK. Opioids and the treatment of chronic pain: controversies, current status, and future directions. Experimental and Clinical Psychopharmacology 2008;16(5):405-16. [DOI: 10.1037/ a0013628]

\section{Stannard 2016}

Stannard C, Moore RA. Traditional opioids for chronic non cancer pain: untidy, unsatisfactory and probably unsuitable. www.evidentlycochrane.net/opioids-chronic-non-cancer-pain/ 2016 (accessed prior to 12 June 2017).

\section{Stinson 2006}

Stinson JN, Kavanagh T, Yamada J, Gill N, Stevens B. Systematic review of the psychometric properties, interpretability and feasibility of self-report pain intensity measures for use in clinical trials in children and adolescents. Pain 2006;125(1-2):143-57. [DOI: 10.1016/j.pain.2006.05.006]

\section{Straube 2008}

Straube S, Derry S, McQuay HJ, Moore RA. Enriched enrolment: definition and effects of enrichment and dose in trials of pregabalin and gabapentin in neuropathic pain. A systematic review. British Journal of Clinical Pharmacology 2008;66(2):266-75. [DOI: 10.1111/j.1365-2125.2008.03200.x]

\section{Straube 2010}

Straube S, Derry S, Moore RA, Paine J, McQuay HJ. Pregabalin in fibromyalgia - responder analysis from individual patient data. BMC Musculoskeletal Disorders 2010;11:150. [DOI: 10.1186/1471-2474-11-150]

\section{Sultan 2008}

Sultan A, Gaskell H, Derry S, Moore RA. Duloxetine for painful diabetic neuropathy and fibromyalgia pain: systematic review of randomised trials. BMC Neurology 2008;8:29. [DOI: 10.1186/1471-2377-8-29]

\section{United Nations 2015}

United Nations. World population prospects 2015 - population indicators. esa.un.org/unpd/wpp/Download/Standard/ Population/ 2015 (accessed 29 February 2016).

\section{Verghese 2010}

Verghese ST, Hannallah RS. Acute pain management in children. Journal of Pain Research 2010;3:105-23. [DOI: 10.2147/ JPR.S4554] 


\section{von Baeyer 2007}

von Baeyer CL, Spagrud LJ. Systematic review of observational (behavioural) measures of pain for children and adolescents aged 3 to 18 years. Pain 2007;127(1-2):140-50. [DOI: 10.1016/ j.pain.2006.08.014]

\section{WHO 2012}

World Health Organization. WHO guidelines on the pharmacological treatment of persisting pain in children with medical illnesses. WHO Press, World Health Organization 2012. [ISBN 978924154812 0]

\section{Wiffen 2017a}

Wiffen PJ, Cooper TE, Anderson AK, Gray A, Gregoire MC, Ljungman $\mathrm{G}$, et al. Opioids for cancer-related pain in children and adolescents. Cochrane Database of Systematic Reviews 2017, Issue 7. [DOI: 10.1002/14651858.CD012564.pub2]

\section{Wiffen 2017b}

Wiffen PJ, Cooper TE, Heathcote L, Clinch J, Howard R, Krane E, et al. Antiepileptic drugs for chronic non-cancer pain in children and adolescents. Cochrane Database of Systematic Reviews 2017, Issue 8. [DOI: 10.1002/14651858.CD012536.pub2]

\section{World Bank 2014}

World Bank. Data - population ages 0-14 (\% of total). data.worldbank.org/indicator/SP.POP.0014.TO.ZS 2014 (accessed 29 February 2016).

\section{CHARACTERISTICS OF STUDIES}

Characteristics of excluded studies [ordered by study ID]

\begin{tabular}{|c|c|}
\hline Study & Reason for exclusion \\
\hline Argoff 2015 & Adult population \\
\hline \multirow[t]{2}{*}{ Berry 1975} & Adult population \\
\hline & Some participants adolescents, unable to contact authors for subunit data \\
\hline \multirow[t]{2}{*}{ Coutinho 1975} & Adult population \\
\hline & Some participants adolescents, unable to contact authors for subunit data \\
\hline \multirow[t]{2}{*}{ Daniel 1971} & Adult population \\
\hline & Some participants adolescents, unable to contact authors for subunit data \\
\hline Frohna 2005 & Acute abdominal pain \\
\hline Gilbert 1978 & Adult population \\
\hline Lapane 2013 & Adult population \\
\hline \multirow[t]{2}{*}{ Mehl-Madrona 1999} & Combination pharmacotherapy \\
\hline & Adult population \\
\hline Middleton 1985 & Adult population \\
\hline Poonai 2014 & Wrong study population; participants were in immediate fracture pain. \\
\hline Rose 2003 & Wrong study population; participants were in immediate fracture pain. \\
\hline Valkenburg 2015 & Aim of the study was not to investigate the efficacy of opioids in children with chronic pain. \\
\hline
\end{tabular}




\section{AP PE N DICES}

\section{Appendix 1. Meeting for NIHR Programme Grant agenda on pain in children \\ Date}

Monday 1st June 2015

\section{Location}

International Association of the Study of Pain (IASP) Conference, Seattle, USA

\section{Delegates}

Allen Finlay, Anna Erskine, Boris Zernikow, Chantal Wood, Christopher Eccleston, Elliot Krane, George Chalkaiadis, Gustaf Ljungman, Jacqui Clinch, Jeffrey Gold, Julia Wager, Marie-Claude Gregoire, Miranda van Tilburg, Navil Sethna, Neil Schechter, Phil Wiffen, Richard Howard, Susie Lord.

\section{Purpose}

National Institute for Health Research (NIHR) (UK) Programme Grant - Addressing the unmet need of chronic pain: providing the evidence for treatments of pain.

\section{Proposal}

Nine reviews in pharmacological interventions for chronic pain in children and adolescents: Children (5 new, 1 update, 1 overview, and 2 rapid) self-management of chronic pain is prioritised by the planned NICE guideline. Pain management (young people and adults) with a focus on initial assessment and management of persistent pain in young people and adults.

We propose titles in paracetamol, ibuprofen, diclofenac, other NSAIDs, and codeine, an overview review on pain in the community, 2 rapid reviews on the pharmacotherapy of chronic pain, and cancer pain, and an update of psychological treatments for chronic pain.

\section{Key outcomes}

The final titles: (1) opioids for cancer-related pain (Wiffen 2017a), (2) opioids for chronic non-cancer pain (Cooper 2017a - this review), (3) antiepileptic drugs for chronic non-cancer pain (Wiffen 2017b), (4) antidepressants for chronic non-cancer pain (Cooper 2017a), (5) non-steroidal anti-inflammatory drugs (NSAIDs) for chronic non-cancer pain (Eccleston 2017), (6) non-steroidal anti-inflammatory drugs (NSAIDs) for cancer-related pain (Cooper 2017b), (7) paracetamol for chronic non-cancer pain (Cooper 2017c).

\section{PICO}

Patients: children, aged 3 to 12 , chronic pain defined as pain persisting for 3 months (NB: now changed to: birth to 17 years to include infants, children and adolescents).

Interventions: by drug class including antiepileptic drugs, antidepressants, opioids, NSAIDs, paracetamol

Comparisons: maintain a separation of cancer and non-cancer, exclude headache, in comparison with placebo and or active control

\section{Outcomes: we will adopt the IMMPACT criteria}

\section{Appendix 2. Methodological considerations for chronic pain}

There have been several recent changes in how the efficacy of conventional and unconventional treatments is assessed in chronic painful conditions. The outcomes are now better defined, particularly with new criteria for what constitutes moderate or substantial benefit (Dworkin 2008); older trials may only report participants with 'any improvement'. Newer trials tend to be larger, avoiding problems from the random play of chance. Newer trials also tend to be of longer duration, up to 12 weeks, and longer trials provide a more rigorous and valid assessment of efficacy in chronic conditions. New standards have evolved for assessing efficacy in neuropathic pain, and we are now applying stricter criteria for the inclusion of trials and assessment of outcomes, and are more aware of problems that may affect our overall assessment. We summarise some of the recent insights that must be considered in this new review.

1. Pain results tend to have a U-shaped distribution rather than a bell-shaped distribution. This is true in acute pain (Moore 2011a; Moore 2011b), back pain (Moore 2010d), and arthritis (Moore 2010c), as well as in fibromyalgia (Straube 2010); in all cases average results usually describe the experience of almost no one in the trial. Data expressed as averages are potentially misleading, unless they can be proven to be suitable.

2. As a consequence, we have to depend on dichotomous results (the individual either has or does not have the outcome) usually from pain changes or patient global assessments. The Initiative on Methods, Measurement, and Pain Assessment in Clinical Trials (IMMPACT) group has helped with their definitions of minimal, moderate, and substantial improvement (Dworkin 2008). In arthritis, trials of less 
than 12 weeks' duration, and especially those shorter than eight weeks, overestimate the effect of treatment (Moore 2010c); the effect is particularly strong for less effective analgesics, and this may also be relevant in neuropathic-type pain.

3. The proportion of patients with at least moderate benefit can be small, even with an effective medicine, falling from $60 \%$ with an effective medicine in arthritis to 30\% in fibromyalgia (Moore 2009; Moore 2010c; Moore 2013b; Moore 2014b; Straube 2008; Sultan 2008). A Cochrane review of pregabalin in neuropathic pain and fibromyalgia demonstrated different response rates for different types of chronic pain (higher in diabetic neuropathy and postherpetic neuralgia and lower in central pain and fibromyalgia) (Moore 2009). This indicates that different neuropathic pain conditions should be treated separately from one another, and that pooling should not be done unless there are good grounds for doing so.

4. Individual patient analyses indicate that patients who get good pain relief (moderate or better) have major benefits in many other outcomes, affecting quality of life in a significant way (Moore 2010b; Moore 2014a).

5. Imputation methods such as last observation carried forward (LOCF), used when participants withdraw from clinical trials, can overstate drug efficacy, especially when adverse event withdrawals with drug are greater than those with placebo (Moore 2012).

\section{Appendix 3. MEDLINE search strategy (via Ovid)}

1. exp Pain/

2. pain.tw.

3. 1 or 2

4. exp Neoplasms/

5. (cancer* or neoplas* or tumo* or carcinoma* or hodgkin* or nonhodgkin* or adenocarcinoma* or leuk?emia* or metasta* or malignan* or lymphoma* or sarcoma* or melanoma* or myeloma* or oncolog*).tw.

6. 4 or 5

7. exp Child/ or exp adolescent/ or exp infant/

8. (child ${ }^{\star}$ or boy ${ }^{\star}$ or girl ${ }^{\star}$ or adolescen* or teen $^{\star}$ or toddler $^{\star}$ or preschooler $^{\star}$ or pre-schooler ${ }^{\star}$ or infant ${ }^{\star}$ or baby or babies).tw.

9. 7 or 8

10. (3 not 6$)$ and 9

11.narcotics/

12.Analgesics, Opioid/

13. (morphine or buprenorphine or codeine or dextromoramide or diphenoxylate or dipipanone or dextropropoxyphene or propoxyphene or diamorphine or dihydrocodeine or alfentanil or fentanyl or remifentanil or meptazinol or methadone or nalbuphine or oxycodone or papaveretum or pentazocine or meperidine or pethidine or phenazocine or hydrocodone or hydromorphone or levorphanol or oxymorphone or butorphanol or dezocine or sufentanil or ketobemidone).tw.

14.or/11-13

15.randomized controlled trial.pt.

16. controlled clinical trial.pt.

17.randomized.ab.

18. placebo.ab.

19.drug therapy.fs.

20.randomly.ab.

21.trial.ab.

22.groups.ab.

23.15 or 16 or 17 or 18 or 19 or 20 or 21 or 22

24.exp animals/ not humans.sh.

25.223 not 24

26.10 and 14 and 25

\section{Appendix 4. Embase search strategy (via Ovid)}

1. exp Pain/

2. pain.tw.

3. 1 or 2

4. exp Neoplasms/

5. (cancer* or neoplas* or tumo* or carcinoma* or hodgkin* or nonhodgkin* or adenocarcinoma* or leuk?emia* or metasta* or malignan* or lymphoma* or sarcoma* or melanoma* or myeloma* or oncolog*).tw.

6. 4 or 5

7. exp Child/ or exp adolescent/ or exp infant/ 
8. (child ${ }^{\star}$ or boy ${ }^{\star}$ or girl ${ }^{\star}$ or adolescen ${ }^{\star}$ or teen ${ }^{\star}$ or toddler ${ }^{\star}$ or preschooler ${ }^{\star}$ or pre-schooler ${ }^{\star}$ or infant ${ }^{\star}$ or baby or babies).tw.

9. 7 or 8

10. (3 not 6) and 9

11.narcotics/

12.Analgesics, Opioid/

13. (morphine or buprenorphine or codeine or dextromoramide or diphenoxylate or dipipanone or dextropropoxyphene or propoxyphene or diamorphine or dihydrocodeine or alfentanil or fentanyl or remifentanil or meptazinol or methadone or nalbuphine or oxycodone or papaveretum or pentazocine or meperidine or pethidine or phenazocine or hydrocodone or hydromorphone or levorphanol or oxymorphone or butorphanol or dezocine or sufentanil or ketobemidone).tw.

14.or/11-13

15. random\$.tw.

16.factorial\$.tw.

17.crossover\$.tw.

18.cross over $\$$.tw.

19.cross-over\$.tw.

20. placebo\$.tw.

21.(doubl\$ adj blind\$).tw.

22. (singl\$ adj blind\$).tw.

23.assign\$.tw.

24.allocat\$.tw.

25.volunteer\$.tw.

26. Crossover Procedure/

27.double-blind procedure.tw.

28.Randomized Controlled Trial/

29.Single Blind Procedure/

30.or/15-29

31.(animal/ or nonhuman/) not human/

32.30 not 31

33.10 and 14 and 32

\section{Appendix 5. CENTRAL search strategy (via the CRSO)}

\#1MESH DESCRIPTOR pain EXPLODE ALL TREES\#2pain*:TI,AB,KY\#3MESH DESCRIPTOR Neoplasms EXPLODE ALL TREES\#4(cancer* or neoplas* or tumo* or carcinoma* or hodgkin* or nonhodgkin* or adenocarcinoma* or leuk?emia* or metasta* or malignan* or lymphoma* or sarcoma* or melanoma* or myeloma* or oncolog*):TI,AB,KY\#5\#1 OR \#2\#6\#3 OR \#4\#7\#5 NOT \#6\#8MESH DESCRIPTOR child EXPLODE ALL TREES\#9MESH DESCRIPTOR infant EXPLODE ALL TREES\#10MESH DESCRIPTOR Adolescent EXPLODE ALL TREES\#11(child* or boy* or girl* or adolescen* or teen ${ }^{\star}$ or toddler ${ }^{\star}$ or preschooler* or pre-schooler ${ }^{\star}$ or baby or babies or infant $\left.{ }^{\star}\right): \mathrm{TI}, \mathrm{AB}, \mathrm{KY} \# 12 \# 8 \mathrm{OR} \# 9$ OR $\# 10$ OR \#11\#13MESH DESCRIPTOR narcotics\#14MESH DESCRIPTOR Analgesics, Opioid\#15(morphine or buprenorphine or codeine or dextromoramide or diphenoxylate or dipipanone or dextropropoxyphene or propoxyphene or diamorphine or dihydrocodeine or alfentanil or fentanyl or remifentanil or meptazinol or methadone or nalbuphine or oxycodone or papaveretum or pentazocine or meperidine or pethidine or phenazocine or hydrocodone or hydromorphone or levorphanol or oxymorphone or butorphanol or dezocine or sufentanil or ketobemidone):TI,AB,KY\#16\#13 OR \#14 OR \#15\#17\#7 AND \#12 AND \#16

\section{Appendix 6. GRADE guidelines}

Some advantages of utilising the GRADE process are (Guyatt 2008):

- transparent process of moving from evidence to recommendations;

- clear separation between quality of evidence and strength of recommendations;

- explicit, comprehensive criteria for downgrading and upgrading quality of evidence ratings; and

- clear, pragmatic interpretation of strong versus weak recommendations for clinicians, patients, and policymakers.

The GRADE system uses the following criteria for assigning grade of evidence:

- high: we are very confident that the true effect lies close to that of the estimate of the effect;

- moderate: we are moderately confident in the effect estimate; the true effect is likely to be close the estimate of effect, but there is a possibility that it is substantially different;

- low: our confidence in the effect estimate is limited; the true effect may be substantially different from the estimate of the effect; and 
- very low: we have very little confidence in the effect estimate; the true effect is likely to be substantially different from the estimate of effect.

We will decrease the grade if there is:

- serious (-1) or very serious (-2) limitation to study quality;

- important inconsistency (-1);

- some (-1) or major (-2) uncertainty about directness;

- imprecise or sparse data (-1); or

- high probability of reporting bias (-1).

We will increase the grade if there is:

- strong evidence of association - significant relative risk of $>2(<0.5)$ based on consistent evidence from two or more observational studies, with no plausible confounders (+1);

- very strong evidence of association - significant relative risk of $>5(<0.2)$ based on direct evidence with no major threats to validity $(+2)$;

- evidence of a dose response gradient $(+1)$; or

- all plausible confounders would have reduced the effect $(+1)$.

"In addition, there may be circumstances where the overall rating for a particular outcome would need to be adjusted per GRADE guidelines (Guyatt 2013a). For example, if there were so few data that the results were highly susceptible to the random play of chance, or if studies used LOCF imputation in circumstances where there were substantial differences in adverse event withdrawals, one would have no confidence in the result, and would need to downgrade the quality of the evidence by three levels, to very low quality. In circumstances where no data were reported for an outcome, we planned to report the level of evidence as 'no evidence to support or refute' (Guyatt 2013b)."

\section{WHAT'S NEW}

\begin{tabular}{lll}
\hline Date & Event & Description \\
\hline 19 February 2020 & Amended & Clarification added to Declarations of interest. \\
\hline 25 March 2019 & Review declared as stable & See Published notes. \\
\hline
\end{tabular}

\section{H IST ORY}

Protocol first published: Issue 2, 2017

Review first published: Issue 7, 2017

\begin{tabular}{lll}
\hline Date & Event & Description \\
\hline 7 June 2019 & Amended & $\begin{array}{l}\text { We amended the GRADE methods for assessing no evidence, for } \\
\text { consistency with the other reviews in this series. }\end{array}$ \\
\hline 4 July 2018 & Amended & $\begin{array}{l}\text { Searches updated with terms relating to 'infants'. We did not } \\
\text { identify any new studies. }\end{array}$ \\
\hline 14 August 2017 & Amended & $\begin{array}{l}\text { References for some reviews from the suite amended to reflect } \\
\text { correct publication Issue. }\end{array}$ \\
\hline
\end{tabular}

\section{CONTRIBUTIONS OF AUTHORS}

TC and PW registered the title.

TC, PW, and Christopher Eccleston wrote the template protocol for the suite of children's reviews, of which this review is a part. 
All authors contributed to writing the protocol, and all authors agreed on the final version.

All authors were responsible for data extraction, analysis, and writing of the Discussion for the full review.

All authors will be responsible for the completion of updates.

\section{DECLARATIONS OF INTEREST}

PW: none known.

TC: none known.

EF: none known.

AG: none known; AG serves on medicines regulatory and selection bodies, and previously contributed to WHO guidance on the management of pain in children.

EK has received consulting fees for attending a research strategy meeting from Pfizer, Inc. (2015) and for protocol and research consultation from Mallinckrodt Pharmaceuticals, Inc. (2014), AstraZeneca, Inc. (2014), and Collegium Pharma (2016); EK is a specialist paediatric pain clinician and treats patients with chronic pain.

NS has received grants from Gebauer Company for conduct of animal studies using a topical anaesthetic (2015). NS has offered consultant expertise to Pfizer in designing a multi-center study for use of gabapentin in treatment of neuropathic pain in children (2015). NS is a coinvestigator with an ongoing multi-center Phase 3 trial of an experimental drug SMNRX [antisense oligonucleotide] for treatment of infants and children with spinal muscle atrophy (2012 to present). NS is an anaesthesiologist and manages paediatric patients with chronic pain.

MvT: none known.

BZ has received personal funding from Grünenthal (2014 to 2016) and Pfizer (2016) in designing and monitoring paediatric investigator plans; BZ is a specialist paediatric pain researcher and clinician and treats patients with cancer pain.

This review was identified in a 2019 audit as not meeting the current definition of the Cochrane Commercial Sponsorship policy. At the time of its publication it was compliant with the interpretation of the existing policy. As with all reviews, new and updated, at update this review will be revised according to 2020 policy update.

\section{SOURCES OF SUPPORT}

\section{Internal sources}

- No sources of support supplied

\section{External sources}

- National Institute for Health Research (NIHR), UK.

NIHR Programme Grant, Award Reference Number: 13/89/29 (Addressing the unmet need of chronic pain: providing the evidence for treatments of pain)

\section{DIFFERENCES BETWEEN PROTOCOL AND REVIEW}

Minor changes to the wording of the Background section and details of examples.

We did not consider studies with fewer than 10 participants per treatment arm for inclusion in this review, as is standard practice for this group.

\section{N O T E S}

A restricted search in March 2019 did not identify any potentially relevant studies likely to change the conclusions. Therefore, this review has now been stabilised following discussion with the authors and editors. The review will be re-assessed for updating in five years. If appropriate, we will update the review before this date if new evidence likely to change the conclusions is published, or if standards change substantially which necessitates major revisions.

\section{NDEX TERMS}

\section{Medical Subject Headings (MeSH)}

Analgesics, Opioid [adverse effects] [*therapeutic use]; Chronic Pain [ ${ }^{*}$ drug therapy] [etiology] 


\section{MeSH check words}

Adolescent; Child; Child, Preschool; Humans; Infant; Infant, Newborn 